\title{
Article \\ Effect of Spring Frost Damage on Apple Fruit (Malus domestica Borkh.) Inner Quality at Harvest
}

\author{
Anka Cebulj ${ }^{1, *(\mathbb{D})}$, Maja Mikulič-Petkovšek ${ }^{2}\left(\mathbb{D}\right.$, Robert Veberič $^{2}\left(\mathbb{D}\right.$ ) and Jerneja Jakopic $^{2}(\mathbb{D}$ \\ 1 Department of Fruit Growing, Viticulture and Oenology, Agricultural Institute of Slovenia, Hacquetova ulica \\ 17, SI-1000 Ljubljana, Slovenia \\ 2 Department of Agronomy, Biotechnical Faculty, University of Ljubljana, Jamnikarjeva 101, \\ SI-1000 Ljubljana, Slovenia; maja.mikulic-petkovsek@bf.uni-lj.si (M.M.-P.); robert.veberic@bf.uni-lj.si (R.V.); \\ jerneja.jakopic@bf.uni-lj.si (J.J.) \\ * Correspondence: anka.cebulj@kis.si
}

Citation: Cebulj, A.;

Mikulič-Petkovšek, M.; Veberič, R.;

Jakopic, J. Effect of Spring Frost

Damage on Apple Fruit (Malus

domestica Borkh.) Inner Quality at

Harvest. Agriculture 2022, 12, 14.

https://doi.org/10.3390/

agriculture12010014

Academic Editor: Daniel Tan

Received: 19 November 2021

Accepted: 20 December 2021

Published: 23 December 2021

Publisher's Note: MDPI stays neutral with regard to jurisdictional claims in published maps and institutional affiliations.

Copyright: () 2021 by the authors Licensee MDPI, Basel, Switzerland. This article is an open access article distributed under the terms and conditions of the Creative Commons Attribution (CC BY) license (https:/ / creativecommons.org/licenses/by/ $4.0 /)$.

\begin{abstract}
In the last few years, spring frosts have become more of a rule than an exception. There are several prevention measures available for growers and numerous are being tested; however, fruitlets are often affected to some extent. One of the more common phenomena is the development of frost rings. The aim of our study was to evaluate how the occurrence of frost rings affects sugar, organic acid, and phenol content in the flesh and phenol content in the peel of cv. 'Gala' apples. The results show that the frost damage from spring frost affects compounds in the peel, as well as in the flesh of ripe apples. The flesh of fruits with frost rings contained higher content of fructose and in the flesh directly under the rings there was higher sorbitol and malic acid content. Additionally, the hydroxycinnamic acid and dihydrochalcone content in apple flesh was also altered by frost. The frost-affected peel had a completely different ratio of phenolic compounds content in comparison to healthy apples. While there was a significantly higher content of hydroxycinnamic acids and dihydrochalcones in the corky peel in comparison to the unaffected peel, the flavonol and anthocyanin content was considerably lower.
\end{abstract}

Keywords: frost rings; sugar; sorbitol; phenolic content

\section{Introduction}

In recent years, the number of warm periods in winters and cold periods in spring has been increasing. This leads to unavoidable late spring frosts which reduce yield in orchards. The frost in 2017, which affected practically all of Europe, was one of the most severe spring frosts in history. The remaining fruits on the trees are usually damaged; periderm formations and cracks appear on the apple skin. The so-called 'frost ring' and 'frost eye' develop on the apple surface; these are russeted bands encircling the fruit which cause constricted growth in defined areas [1].

While winter frost is more deadly to a tree and is thus the limiting factor of crop cultivation, spring frost leads to crop loss in established orchards [2]. When temperatures drop below $0{ }^{\circ} \mathrm{C}$, ice crystals start to form in the floral organs. When the crystals grow from extracellular space through membranes to the cell core, this causes cell death. Brown discoloration at the ovary after the thawing of apple flowers is the first sign of frost damage. The discoloration may extend both to the style and to the ovary $[1,3,4]$. A kind of deformation that is similar to frost rings is russeting. Russeting is thought to occur during the fruit expansion, where rapid sigmoidal cell expansion in the fruit strains the cuticle and leads to microcracking and results in the formation of a waterproofing periderm layer, consisting mainly of suberin $[5,6]$. Russeting can also develop due to other weather conditions and factors, such as improper use of chemicals and mechanical injury or pest damage [7]. It is also a known trait of some cultivars, such as the 'Renette Canada', a few 'Golden Delicious' strains and others, but it is mostly an undesirable trait in the fruit 
market. This might change in the future due to recent studies on apples with russet. Busatto et al. [8] confirm a higher content of secondary metabolites in the peel of apples with russet. With growing awareness of the beneficial effect of the phenolic compound intake on our health [9], this is important information for further studies and breeding. Even the latest reports on russet in apples suggest that this may be a rather good trait, at least as far as human nutrition is concerned [8,10]. However, russet reduces storage life [11] and, for now, reduces the value of apples in the fresh market and is, therefore, prevented with gibberellins wherever possible [12].

There is research on how spring frost affects apples [3,4,13], but information regarding the effect on fruit quality is scarce. Warrington et al. [14] report that low temperatures in the first 40 days after bloom (DAFB) induce smaller fruits. Climate change also affects apples. The tastes and textural attributes of apples have changed due to global warming. Organic acid concentration, fruit firmness and watercore occurrence have decreased and, in some cases, soluble solids have increased in recent years [15]. We wanted to add to the existing body of knowledge with research on how the inner fruit quality of apples damaged by spring frost. The aim of this study was to evaluate how the occurrence of frost rings affects the sugar, organic acid, and phenol content in the flesh and peel of cv. 'Gala' apples. The parameters were chosen because the content of sugars and organic acids-and especially their ratio- have a major effect on apple taste perception. Phenolics are increased in apples with russet and are currently the subject of many researches on their influence on human health.

\section{Materials and Methods}

\subsection{Plant Material}

The study was carried out on the cultivar 'Gala' apples in a year with spring frost. The apple trees were planted in 2003 and are grown on MM106 rootstock. During flowering time, the night temperatures dropped to $-1.1{ }^{\circ} \mathrm{C}$ (measured on $2 \mathrm{~m}$ of height), followed by $20 \mathrm{~cm}$ of snow on the following day. The trees were in the fruit growth stage of an end of flowering $(G)$. The apples were harvested at technological maturity (determined with tests on the ion-starch, fruit firmness, and soluble solids) on 25 September in an orchard located in the north-west part of Slovenia (latitude $46^{\circ} 20^{\prime} \mathrm{N}$, longitude $14^{\circ} 12^{\prime} \mathrm{E}$, altitude $500 \mathrm{~m}$ ). Two types of fruits were collected: fruits with frost damage (FD) that had the so-called 'frost ring', and undamaged apples (C). Both types were exposed to the low temperatures during spring frost, but the apples within the control group had no visible damage and were therefore classified as first quality fruits and comprised the control group in our experiment. Samples from frost-damaged apples were divided into: peel samples (healthy peel (FD-P1), discoloured boundary (FD-P2), and corky peel (FD-P3) (Figure 1)); and flesh samples (flesh underneath healthy peel (FD-F1) and flesh underneath corky peel (FD-F2)). The flesh samples were sampled a few millimetres under the peel. Samples of undamaged apples consisted of a peel sample (C-P) and a flesh sample (C-F). The samples of control apples were taken from the equatorial plane (where the frost rings usually appear). Apple peels and flesh samples were collected according to the above determined treatments and immersed in liquid nitrogen. Frozen samples were stored at $-80{ }^{\circ} \mathrm{C}$ until further analyses.

\subsection{Extraction and Determination of Individual Sugars and Organic Acids}

Frozen samples, comprising of $2 \mathrm{~g}$ of flesh, were chopped and ground for the extraction in $10 \mathrm{~mL}$ of double-distilled water. Further extraction steps were performed in accordance with the description by Zupan et al. [16].

Analyses of sugars and organic acids were performed using a Thermo Finnigan Surveyor HPLC system (Thermo Scientific, San Jose, CA, USA). Rezex RCM-monosaccharide $(300 \times 7.8 \mathrm{~mm}$; Thermo Scientific, San Jose, CA, USA) and Rezex ROA organic acid columns $(300 \times 7.8 \mathrm{~mm}$; Phenomenex, Torrance, CA, USA $)$ were used for sugar and organic acid analyses. Instrument settings were in accordance with the description by Mikulic-Petkovsek et al. [17]. 


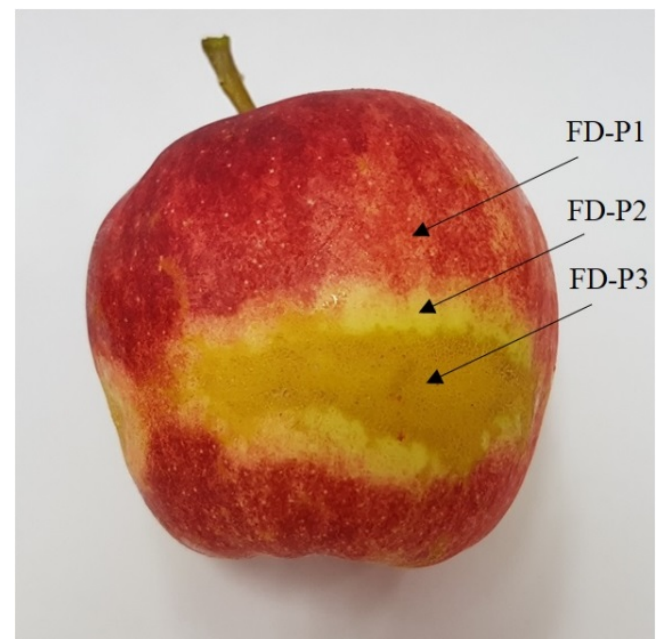

Figure 1. Peel samples from frost damaged apples: healthy peel (FD-P1), discoloured boundary (FD-P2), corky peel (FD-P3).

\subsection{Extraction and Determination of Individual Phenolic Compounds}

For the extraction, $2 \mathrm{~g}$ of flesh and $0.5 \mathrm{~g}$ of peel were chopped into small pieces and phenolic compounds were extracted with $2 \mathrm{~mL}$ and $3 \mathrm{~mL}$ of methanol (Sigma-Aldrich, Steinheim, Germany), containing 3\% ( $v / v)$ formic acid (Fluka Chemie, Buch, Switzerland), respectively. Further extraction steps and HPLC-MS analysis followed the methodology described by Mikulic-Petkovsek et al. [17].

\subsection{Statistics}

Six samples were taken for each treatment, and each sample was combined from two apples. The results were statistically analysed with the Statgraphics Centurion XV (StatPoint, Inc., Warrenton, VA, USA, v. 15.2.14) program, using one-way analysis of variance (ANOVA) to interpret the effect of the treatments. The differences in the content levels were estimated with Duncan's test, and $p$-values of less than or equal to 0.05 were considered statistically significant.

\section{Results}

\subsection{Sugars and Organic Acids in Apple Flesh}

Sugars and organic acids were determined only in the apple flesh. The contents of sucrose, glucose, fructose and sorbitol were determined, and their sum calculated (Table 1). Fructose accounts for the largest proportion of sugars, and it was precisely the fructose content that had statistically significantly variation in both FD-F1 and FD-F2 from C-F. Flesh of frost-affected apples contained higher fructose content, not only underneath the corky tissue, but also under the healthy peel. There was more than $10 \%$ higher fructose content in comparison to undamaged apples. There were small, not statistically significant differences in terms of the sucrose content, whereas the glucose content was similar between samples. There were, however, differences in the sorbitol content; about 33\% higher content was determined in FD-F2 in comparison to C-F. The sum of sugars was not significantly different between the different flesh samples.

The individual contents and sum of three organic acids were determined: malic, citric and shikimic acid (Table 2). There was a difference in malic and citric acid content, and consequently also in the sum of organic acids. The FD-F2 flesh had a higher organic acid content in comparison to other two samples, in particular because of a higher malic acid content. The sugar/organic acid ratio was 18.7, 20.0 and 17.5 for C-F, FD-F1 and FD-F2, respectively. There were no statistical differences. 
Table 1. The content of individual sugars and sum of sugars: sucrose, glucose, fructose and sorbitol (mean $\pm \mathrm{SE}$ in $\mathrm{g} \mathrm{kg}^{-1}$ fresh weight) in flesh of undamaged apples (C-F), and damaged apples: flesh underneath healthy peel (FD-F1) and flesh underneath corky peel (FD-F2). Different letters in the columns denote statistical differences between treatments (the Duncan test, $p<0.05$ ).

\begin{tabular}{|c|c|c|c|c|c|c|c|c|c|c|}
\hline & Sucrose & & Glucose & & Fructose & & Sorbitol & & Sum of Sugars & \\
\hline C-F & $41.52 \pm 2.17$ & a & $6.31 \pm 0.34$ & a & $46.51 \pm 0.83$ & a & $0.91 \pm 0.08$ & a & $95.24 \pm 2.55$ & $\mathrm{a}$ \\
\hline FD-F1 & $35.10 \pm 2.00$ & a & $6.84 \pm 0.52$ & a & $52.79 \pm 1.76$ & $b$ & $0.94 \pm 0.06$ & a & $95.64 \pm 2.95$ & $\mathrm{a}$ \\
\hline FD-F2 & $38.77 \pm 1.63$ & a & $6.51 \pm 0.23$ & a & $55.43 \pm 1.17$ & $b$ & $1.21 \pm 0.04$ & $\mathrm{~b}$ & $101.92 \pm 1.25$ & a \\
\hline
\end{tabular}

Table 2. The content of individual organic acids and the sum of organic acids: malic acid, citric acid, shikimic acid (mean $\pm \mathrm{SE}$ in $\mathrm{g} \mathrm{kg}^{-1}$ fresh weight) in flesh of undamaged apples (C-F), and damaged apples: flesh underneath healthy peel (FD-F1) and flesh underneath corky peel (FD-F2). Different letters in the columns denote statistical differences between treatments (the Duncan test, $p<0.05$ ).

\begin{tabular}{cccccccc}
\hline & Malic Acid & & Citric Acid & & Shikimic Acid & \multicolumn{2}{c}{ Sum of Organic Acids } \\
\hline C-F & $4.78 \pm 0.06$ & a & $0.36 \pm 0.04$ & ab & $0.02 \pm 0$ & a & $5.09 \pm 0.10$ \\
FD-F1 & $4.42 \pm 0.34$ & a & $0.35 \pm 0.05$ & a & $0.02 \pm 0$ & a & $4.78 \pm 0.35$ \\
FD-F2 & $5.41 \pm 0.17$ & b & $0.47 \pm 0.04$ & b & $0.02 \pm 0$ & a & $5.83 \pm 0.23$ \\
\hline
\end{tabular}

\subsection{Phenolic Content in Apple Flesh and Peel}

The content of phenolic compounds was determined separately in apple flesh and peel because it is known that there is a much higher content of phenolic compounds in the peel when compared to the flesh [18]. The results for the flesh are presented in Figure 2. Individually determined phenolic compounds were congregated into four groups: hydroxycinnamic acids (chlorogenic acid, 4-caffeoylquinic acid-4CQA, 5-caffeoylquinic acid 2-5CQA 2 and 4-p-coumaroylquinic acid), dihydrochalcones (3-hydroxy-phloretin-2'-Oxyloglucoside, phloretin-2-O-(2"O-xyloglucoside) and phloridzin), flavonols (quercetin 3-galactoside) and flavan-3-ols (procyanidin dimer B1, procyanidin dimer B2, five procyanidin trimers, catechin and epicatechin). There were statistically significant differences between FD-F1 and FD-F2 in the content of two phenolic groups, dihydrochalcones and hydroxycinnamic acids, whereas C-F was somewhere in the middle. There were no statistically significant differences in the content of flavonols, flavan-3-ols and in the sum of all quantified phenolics.

Just like in the apple flesh, the phenols in the peel were grouped together into four groups with the addition of anthocyanin. In addition to all of the phenolics from flesh, the following phenolics were determined in the peel: hydroxycinnamic acids ( $p$ coumaric acid hexoside and sinapic acid glycoside), flavonols (quercetin 3-rutinoside, quercetin 3-glucoside, quercetin 3-xyloside, quercetin 3-arabinopyranoside, quercetin 3arabinofuranoside, quercetin 3-rhamnoside), flavan-3-ols (procyanidin tetramers 1-4) and anthocyanin (cyanidin galactoside) (Figure 3). Among the hydroxycinnamic acids, FD-P3 stands out. The most significant difference between samples is due to the chlorogenic acid content in FD-P3. The 4CQA content was also higher in the affected part, but there was a lower content of p-coumaric acid hexoside and sinapic acid glycoside in the corky peel. In addition, the sum of dihydrochalcones stands out in FD-P3, with phloridzin and with phloretin-2'-O-xylosilglucoside having higher content. On the other hand, we have flavonols showing a completely different picture. The FD-P3 has the lowest content, and FD-P1 has the highest-even higher than C-P. The highest difference is in quercetin 3-rhamnoside content. The content of flavan-3-ols is the highest in FD-P1 followed by C-P and FD-P3 and is the lowest in FD-P2. The content of flavonols and flavan-3-ols in FD-P1 is higher because of a relatively higher proportion of all phenols in the group and not just one predominantly increased compound as with hydroxycinnamic acids and dihydrochalcones. There is a significantly lower content of anthocyanins in FD-P3, but the other three samples show no statistically significant differences between them. The sum of phenolics is 
statistically significantly lower in FD-P2, while C-P, FD-P1 and FD-P3 have no significant differences in the sum of the phenolic content.
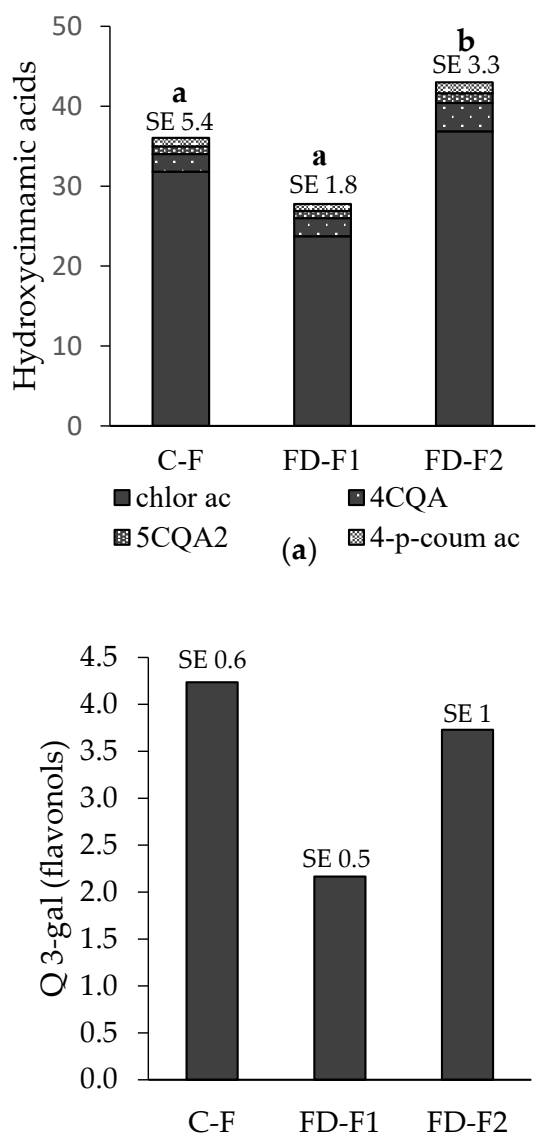

(c)

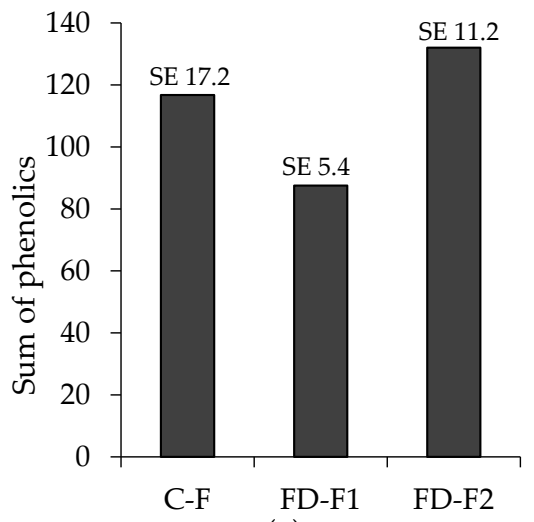

(e)

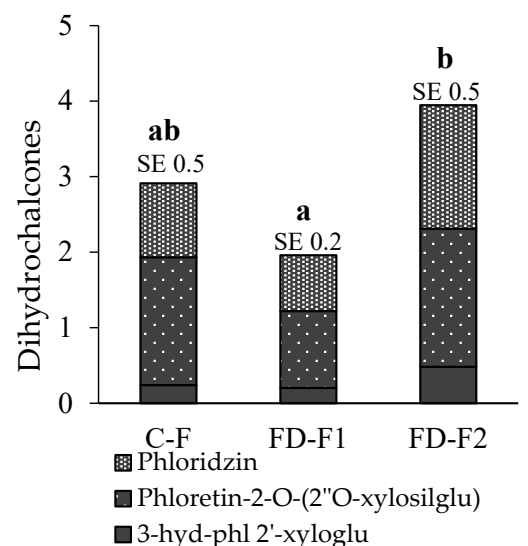

(b)

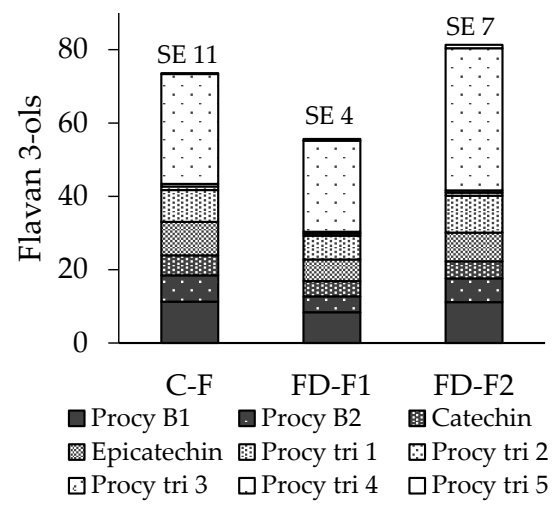

(d)

Figure 2. Content of individual phenolic compounds (mean $\pm \mathrm{SE}$ in $\mathrm{mg} \mathrm{kg}^{-1}$ fresh weight), shown in groups: (a) hydroxycinnamic acids (chlor ac, chlorogenic acid; 4CQA, 4-caffeoylquinic acid; 5CQA2, 5-caffeoylquinic acid 2; 4-O-p-coum ac, 4-p-coumaroylquinic acid); (b) dihydrochalcones (3-hyd-phl 2'-xylglu, 3-hydroxy-phloretin-2'-O-xyloglucoside; phloretin-2-O-(2"O-xylosilglu, phloretin-2-O-(2"Oxyloglucoside); phloridzin); (c) flavonols (Q 3-gal, quercetin 3-galactoside); (d) flavan-3-ols (procy B1, procyanidin dimer B1; procy B2, procyanidin dimer B2; procy tri 1-5, five procyanidin trimers; catechin; epicatechin); and (e) sum of all phenolics in flesh of undamaged apples (C-F) and damaged apples: flesh underneath healthy peel (FD-F1) and flesh underneath corky peel (FD-F2). Different letters above columns denote statistical differences between treatments (the Duncan test. $p<0.05$ ). 


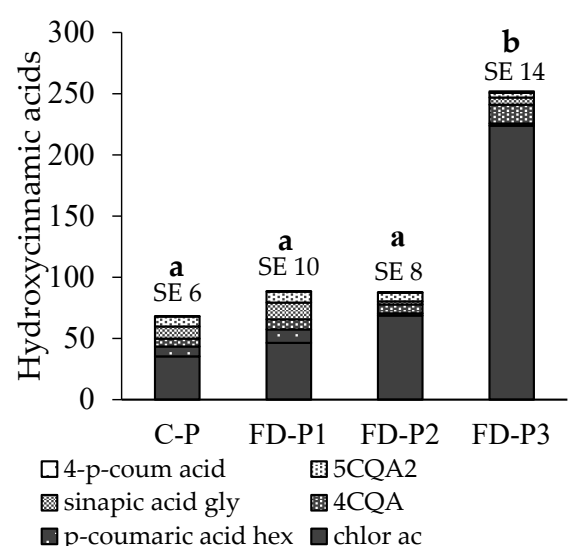

(a)

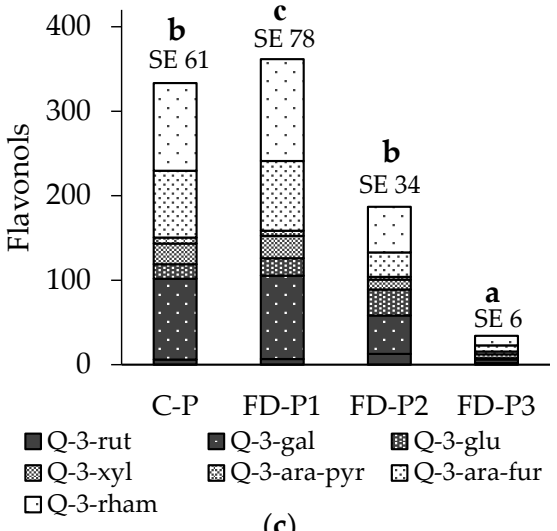

(c)

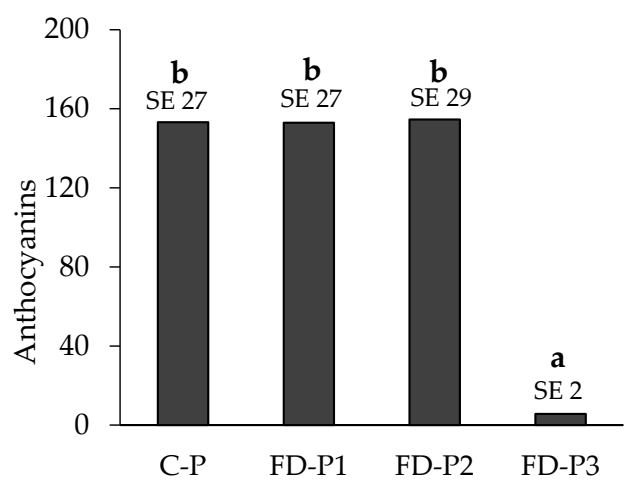

(e)
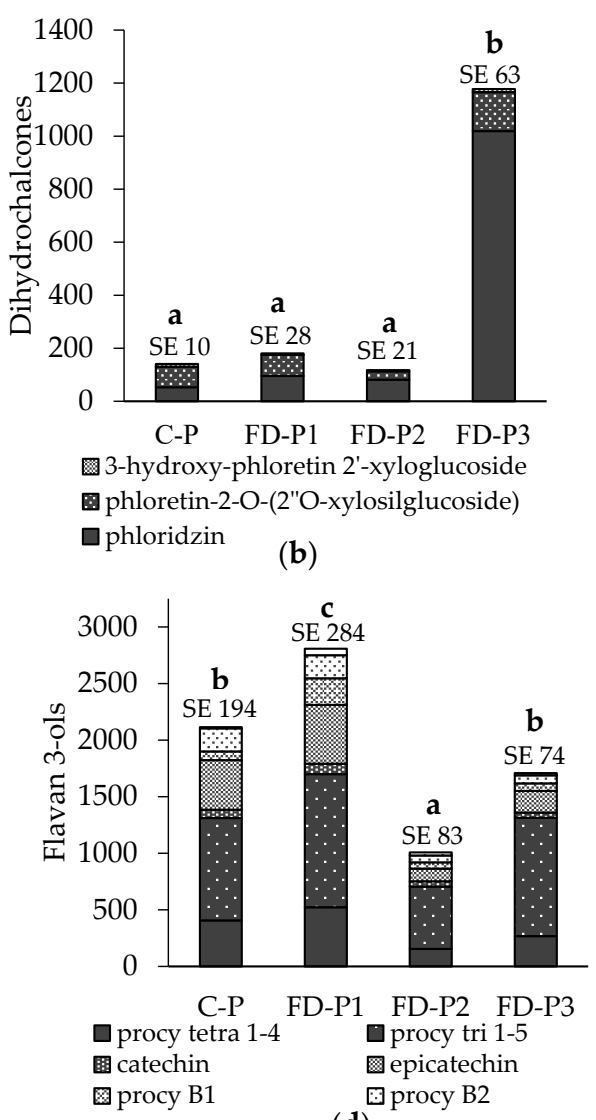

(d)

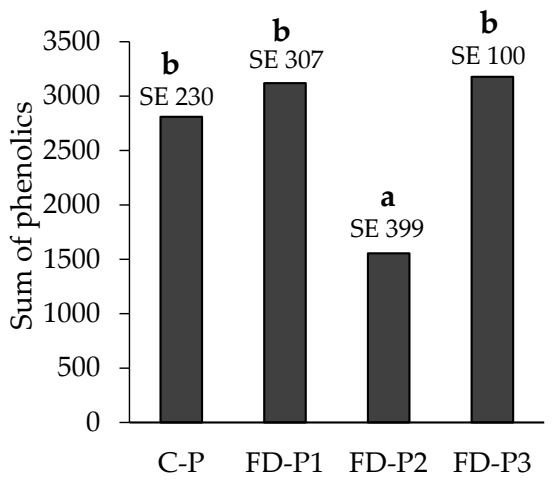

(f)

Figure 3. Content of individual phenolic compounds (mean $\pm \mathrm{SE}$ in $\mathrm{mg} \mathrm{kg}^{-1}$ fresh weight) shown in groups: (a) hydroxycinnamic acids (p-coumaric acid hex, p-coumaric acid hexoside; chlor ac, chlorogenic acid; 4CQA, 4-caffeoylquinic acid; 5CQA2, 5-caffeoylquinic acid 2; sinapic acid gly, sinapic acid glycoside; 4-O-p-coum ac, 4-p-coumaroylquinic acid); (b) dihydrochalcones (3-hydroxy-phloretin-2' O-xyloglucoside; phloretin-2-O-(2"O-xyloglucoside); phloridzin); (c) flavonols (Q-3-rut, quercetin 3-rutinoside; Q-3-gal, quercetin 3-galactoside; Q-3-glu, quercetin 3-glucoside; Q-3-xyl, quercetin 3-xyloside; Q-3-ara-pyr, quercetin 3-arabinopyranoside, Q-3-ara-fur, quercetin 3-arabinofuranoside; Q-3-rham, quercetin 3-rhamnoside); (d) flavan-3-ols (procy B1, procyanidin dimer B1; procy B2, procyanidin dimer B2; procy tri 1-5, five procyanidin trimers; procy tetra 1-4, four procyanidin tetramers; catechin; epicatechin); anthocyanins (cyanidin-3-galactoside); (e) anthocyanins; and (f) the sum of all phenolics in the apple peel of undamaged apples (C-P) and the frost-damaged apples: healthy peel (FD-P1), discoloured boundary (FD-P2), corky peel (FD-P3). Different letters above columns denote statistical differences between treatments (the Duncan test. $p<0.05$ ). 


\section{Discussion}

Carbohydrates are essential to the quality and yield of fruit. Fructose and sucrose are the major soluble sugars in apple; sorbitol is the major sugar alcohol $[18,19]$. When carbohydrates are synthesized in leaves, they are transported to the fruits via sorbitol and sucrose, with sorbitol as a predominant transportation form. In apple fruit, sorbitol is converted into fructose [20]. The content of both was higher in FD-F2 flesh in comparison to C-F flesh. Sorbitol content is also higher in FD-F2 in comparison to FD-F1. Sorbitol is known for its accumulation in dormant buds and tissues of Rosaceae trees [21]. Sugar alcohols are associated with the development of tolerance to drought, salt, low temperatures, and related stresses [22]. Higher sorbitol content in leaves was observed in connection to drought resistance [23]. Our results suggest that spring frost damage also affects the sorbitol content in the damaged tissue of mature apple fruits; however, further research is needed to shed some light on the mechanisms behind this. The amount of sorbitol can greatly influence the perceived sweetness of apples. It has been shown by Aprea et al. [24] that sorbitol content correlates with perceived sweetness better than any other single sugar or total sugar content.

Malic acid, the predominant organic acid in an apple [19], has the greatest impact on the perception of flesh sourness. Furthermore, malate, the ionic form of malic acid, is a central metabolite involved in cell function [25], among others also as an osmoticum for plant cells to increase cold tolerance [26]. Several biochemical pathways are involved in the synthesis and metabolism of malate [27]. The acidity depends on the stored malate in the vacuole, which depends on acidity level of the vacuole and transporters for malate to vacuole. The genes encoding for transporters for apple have already been identified and the role confirmed [28-30], and recent research on genetic control and coordination has shown a complex network of regulating and signalling genes that include MYB genes, including MdMYB73, which is, among others, influenced by the MdCIbHLH1 gene involved in cold tolerance $[29,31]$. This physiology behind the apple acidity might explain the difference in malic acid content underneath the corky peel, but it needs to be thoroughly addressed in future studies to establish the mechanism behind it. Regardless of the cause behind the higher content of malic acid, it can, however, influence the perceived taste of apples. Perceived sweetness is greatly influenced by the acidity and vice versa [32]. The sugar/organic acid ratio is also one of the factors of taste perception. The highest ratio was in FD-F2 flesh, which suggests a sweeter taste, but with no statistical differences. Further research should be undertaken in the context of taste perception.

The content of phenolic compounds is highly influenced by stress, as they are actively involved in defence mechanisms against biotic and abiotic stress [33,34]. The increased content of phenolic compounds is a result of higher activity of enzymes involved in their biosynthesis. Not only does the activity of enzymes involved in phenol synthesis increase during stress, the phosphoenolpyruvate (PEP)-carboxyl-ase activity increases also, which suggests a shift from the production of sucrose to metabolic processes supporting defence and repair [35]. Regarding the influence of spring frost damage on phenolic content in ripe apples, it appears that the content is influenced by frost damage. In apple flesh, the FD-F1 had a significantly lower content of hydroxycinnamic acids and dihydrochalcones in comparison to FD-F2. Busatto et al. [8] have determined a higher content of procyanidin B2 + $\mathrm{B} 4$ and phloridzin in the apple flesh of apples with russet. Our results on dihydrochalcones are in accordance with these results, which suggest an influence of russet formation on phloridzin content, but there were no statistically significant differences in flavan-3-ol content. Even though the difference between the samples in the sum of phenolics was not statistically significant, one can see the indicated trend, a higher content in FD-F2 and a lower content in FD-F1 in comparison to C-F.

The apple peel is severely affected by the frost, and therefore the influence on phenolic content is not that surprising. However, what is interesting is the different response of phenolic groups to the deformation. While the content of hydroxycinnamic acids and dihydrochalcones is highest in FD-P3, the flavonol and flavan-3-ol contents are highest in 
FD-P1. The sum of phenolics is equal in all but in FD-P2, indicating the border between the healthy and corky peel. The content of hydroxycinnamic acids in FD-P3 is higher mainly due to the greater chlorogenic acid content. Chlorogenic acid is known for its increase during stress situations, caused either by pests [36], disease [37] or disorders [38]. In a recent study, Gutierrez et al. [39] reported on the positive correlation between chlorogenic acid content and russeting, which was also confirmed by Busatto et al. [8]. Like chlorogenic acid, phloridzin was also found to be increased in apple peels with russet $[8,39]$. In the study by Gutierrez et al. [39], linear modelling revealed that russet and genotype explained 38and $36 \%$ of the variation in the peel's phloridzin content in 'Golden Delicious' apples and its sports. The cultivar 'Gala' does not develop russet under normal growing conditions; therefore, increased phloridzin content can be attributed mainly to the development of frost rings. Phloridzin is involved in the disease resistance [40]; its increase could thereby increase the protection of affected tissue.

While some phenolic compounds, such as chlorogenic acid, are key components to lignin and suberin pathways, their expression may inhibit specific classes of phenolics [41]. This might explain the lower content of flavonols FD-P2 and FD-P3. Gutierrez et al. [39] also found a negative correlation between russet and the flavonol content. Flavan-3-ols were the lowest in FD-P2, which seems to be the most affected part of the peel with the least of phenolics. This phenomenon in frost rings might be explained by higher synthesis of dihydrochalcones and hydroxycinnamic acids. On the other hand, we have the highest content of flavan-3-ols in FD-P1. The sum of phenolics shows us that the FD-P2 was truly the most affected and that other peel samples seem to be comparable in the content of phenolics. However, we can see that the distribution of phenolic groups varies greatly between samples.

\section{Conclusions}

Frost damage did not only affect the peel, but also the flesh. The flesh of fruits with frost rings contained a higher content of fructose and, directly under the rings, also sorbitol and malic acid. Additionally, we confirmed that hydroxycinnamic acids and the dihydrochalcone content in the apple flesh were altered by frost. The frost-affected peel had a completely different ratio of phenolic compounds content in comparison to undamaged apples. While there was a significantly higher content of hydroxycinnamic acids and dihydrochalcones in comparison to the unaffected peel, the flavonol content was considerably lower. With these results, we have fairly contributed to the knowledge on fruit quality and on how frost alters the fruit's metabolites.

Author Contributions: Conceptualization, A.C. and R.V.; methodology, A.C., M.M.-P. and R.V.; software, J.J.; validation, M.M.-P., R.V. and J.J.; formal analysis, M.M.-P. and A.C.; investigation, A.C.; resources, R.V.; data curation, J.J. and R.V.; writing—original draft preparation, A.C.; writing-review and editing, J.J. and R.V.; visualization, A.C.; supervision, J.J. and R.V.; project administration, R.V.; funding acquisition, R.V. All authors have read and agreed to the published version of the manuscript.

Funding: This work was funded by the Slovenian Research Agency (grants Horticulture No. P4-0013 and P4-0133 Sustainable Agriculture).

Data Availability Statement: Not applicable.

Acknowledgments: The authors are grateful to staff from Sadovnjak Resje (KGZ Sava z.o.o.) for acquiring the apples for this research.

Conflicts of Interest: The authors declare no conflict of interest. The funders had no role in the design of the study; in the collection, analyses, or interpretation of data; in the writing of the manuscript, or in the decision to publish the results. 


\section{References}

1. Rodrigo, J. Spring frosts in deciduous fruit trees-Morphological damage and flower hardiness. Sci. Hortic. 2000, 85, 55-173. [CrossRef]

2. Byers, R.E.; Marini, R.P. Influence of blossom and fruit thinning on peach flower bud tolerance to an early spring freeze. HortScience 1994, 29, 146-148. [CrossRef]

3. Eccel, E.; Rea, R.; Caffarra, A.; Crisci, A. Risk of spring frost to apple production under future climate scenarios: The role of phenological acclimation. Int. J. Biometeorol. 2009, 53, 273-286. [CrossRef]

4. Blanke, M.M.; Kunz, A. Effects of climate change on pome fruit phenology and precipitation. Acta Hortic. 2011, 922, 381-386. [CrossRef]

5. Ginzberg, I.; Stern, R.A. Strengthening fruit-skin resistance to growth strain by application of plant growth regulators. Sci. Hortic. 2016, 198, 150-153. [CrossRef]

6. Khanal, B.P.; Grimm, E.; Knoche, M. Russeting in apple and pear: A plastic periderm replaces a stiff cuticule. AoB Plants 2013, 5, pls048. [CrossRef] [PubMed]

7. Musacchi, S.; Serra, S. Apple fruit quality: Overview on pre-harvest factors. Sci. Hortic. 2018, 234, 409-430. [CrossRef]

8. Busatto, N.; Matsumoto, D.; Tadiello, A.; Vrhovsek, U.; Costa, F. Multifaced analyses disclose the role of fruit size and skinrusseting in the accumulation pattern of phenolic compounds in apple. PLoS ONE 2019, 14, e219354. [CrossRef]

9. Hyson, D.A. A Comprehensive review of apples and apple components and their relationship to human health. Adv. Nutr. 2011, 2, 408-420. [CrossRef]

10. Andre, C.M.; Larsen, L.; Burgess, E.J.; Jensen, D.J.; Cooney, J.M.; Evers, D.; Zhang, J.; Perry, N.B.; Laing, W.A. Unusual immunomodulatory triterpene-caffeates in the skins of russeted varieties of apples and pears. J. Agric. Food Chem. 2013, 61, 2773-2779. [CrossRef]

11. Faust, M.; Shear, C.B. Russeting of apples, an interpretive review. Hortic. Sci. 1972, 7, 233-235.

12. Eccher, T.; Hajnaajar, H. Fluctuations of entogenous gibberellin A4 and A7 content in apple fruits with different sensitivity to russet. Acta Hortic. 2006, 727, 537-543. [CrossRef]

13. Hoffmann, H.; Rath, T. Future bloom and blossom frost risk for Malus domestica considering climate model and impact model uncertainties. PLOS ONE 2013, 8, e75033.

14. Warrington, I.J.; Fulton TAHalligan, E.A.; de Silva, H.N. Apple Fruit Growth and Maturity are Affected by Early Season Temperatures. J. Am. Soc. Hortic. Sci. 1999, 124, 468-477. [CrossRef]

15. Sugiura, T.; Ogawa, H.; Fukuda, N.; Mariguchi, T. Changes in the taste and textural attributes of apples in response to climate change. Sci. Rep. 2013, 3, 2418. [CrossRef]

16. Zupan, A.; Mikulic-Petkovsek, M.; Stampar, F.; Veberic, R. Sugar and phenol content in apple with or without watercore. J. Sci. Food Agric. 2015, 96, 2845-2850. [CrossRef] [PubMed]

17. Mikulic-Petkovsek, M.; Stampar, F.; Veberic, R. Parameters of inner quality of the apple scab resistant and susceptible apple cultivars (Malus domestica Borkh.). Sci. Hortic. 2007, 114, 37-44. [CrossRef]

18. Zhang, Y.; Li, P.; Cheng, L. Developmental changes of carbohydrates, organic acids, amino acids, and phenolic compounds in 'Honeycrisp' apple flesh. Food Chem. 2010, 123, 1013-1018. [CrossRef]

19. Cebulj, A.; Cunja, V.; Mikulic-Petkovsek, M.; Veberic, R. Importance of metabolite distribution in apple fruit. Sci. Hortic. 2017, 214, 214-220. [CrossRef]

20. Cheng, L.; Zhou, R.; Reidel, E.J.; Sharkey, T.D.; Dandekar, A.M. Antisense inhibition of sorbitol synthesis leads to up-regulation of starch synthesis without altering CO2 assimilation in apple leaves. Planta 2005, 220, 767-776. [CrossRef]

21. Whetter, J.M.; Taper, C.D. Occurrence of sorbitol (D-glucitol) and certain related sugars in germinating seeds and developing seedlings of Malus. Can. J. Bot. 1966, 44, 51-55. [CrossRef]

22. Loescher, W.H.; Everard, J.D. Regulation of sugar alcohol biosynthesis. In Photosynthesis. Advances in Photosynthesis and Respiration; Leegood, R.C., Sharkey, T.D., von Caemmerer, S., Eds.; Springer: Dordrecht, The Netherlands, 2000; Volume 9, pp. $275-299$.

23. Li, F.; Lei, H.; Zhao, X.; Shen, X.; Lium, A.; Li, T. Isolation and characterisation of two sorbitol transporter gene promoters in micropropagated apple plants (Malus $\times$ domestica) regulated by drought stress. Plant Growth Regul. 2012, 68, 475-482. [CrossRef]

24. Aprea, E.; Charles, M.; Endrizzi, I.; Corollaro, M.L.; Betta, E.; Biasioli, F.; Gasperi, F. Sweet taste in apples: The role of sorbitol, individual sugars, organic acids and volatile compounds. Sci. Rep. 2017, 7, 44950. [CrossRef]

25. Fernie, A.R.; Martinoia, E. Malate. Jack of all trades or master of a few? Phytochemistry 2009, 70, 828-832. [CrossRef] [PubMed]

26. Hu, D.-G.; Ma, Q.-J.; Sun, C.-H.; Sun, M.-H.; You, C.-X.; Hao, Y.-J. Overexpression of MdSOS2L1, a CIPK protein kinase, increases the antioxidant metabolites to enhance salt tolerance in apple and tomato. Physiol. Plantarum. 2016, 156, 201-214. [CrossRef]

27. Etienne, A.; Génard, M.; Lobit, P.; Mbeguié-A-Mbéguié, D.; Bugaud, C. What controls fleshy fruit acidity? A review of malate and citrate accumulation in fruit cells. J. Exp. Bot. 2013, 64, 1451-1469. [CrossRef]

28. Hu, D.-G.; Sun, C.-H.; Ma, Q.-J.; You, C.-X.; Cheng, L.; Hao, Y.-J. MdMYB1 regulates anthocyanin and malate accumulation by directly facilitating their transport into vacuoles in apples. Plant Physiol. 2016, 170, 1315-1330. [CrossRef] [PubMed]

29. Hu, D.-G.; Li, Y.-Y.; Zhang, Q.-Y.; Li, M.; Sun, C.-H.; Yu, J.-Q.; Hao, Y.-J. The R2R3-MYB transcription factor MdMYB 73 is involved in malate accumulation and vacuolar acidification in apple. Plant J. 2017, 91, 443-454. [CrossRef]

30. Jia, D.; Shen, F.; Wang, Y.; Wu, T.; Xu, X.; Zhang, X.; Han, Z. Apple fruit acidity is genetically diversified by natural variations in three hierarchical epistatic genes: MdSAUR37, MdPP2CH and MdALMTII. Plant J. 2018, 95, 427-443. [CrossRef] 
31. Verma, S.; Evans, K.; Guan, Y.; Luby, J.J.; Rosyara, U.R.; Howard, N.P.; Bassil, N.; Bink, M.C.A.M.; van de Weg, W.E.; Peace, C.P. Two large-effect QTLs, $M a$ and Ma3, determine genetic potential for acidity in apple fruit: Breeding insights from a multi-family study. Tree Genet. Genomes 2019, 15, 18. [CrossRef]

32. Rymenants, M.; van de Weg, E.; Auwerkerken, A.; De Wit, I.; Czech, A.; Nijland, B.; Heuven, H.; De Storme, N.; Keulemans, W. Detection of QTL for apple fruit acidity and sweetness using sensorial evaluation in multiple pedigreed full-sib families. Tree Genet. Genomes 2020, 16, 71. [CrossRef]

33. Treutter, D. Significance of flavonoids in plant resistance: A review. Environ. Chem. Lett. 2006, 4, 147-157. [CrossRef]

34. Naikoo, M.I.; Dar, M.I.; Raghib, F.; Jaleel, H.; Ahmad, B.; Raina, A.; Khan, F.A.; Naushin, F. Role and regulation of plants phenolics in abiotic stress tolerance: An overview. In Plant Signaling Molecules; Elsevier: Amsterdam, The Netherlands, 2019; pp. 157-168.

35. Lattanzio, V. Phenolic compounds: Introduction. In Natural Products; Ramawat, K., Merillon, J.M., Eds.; Springer: Berlin, Germany, 2013; pp. 1543-1580.

36. Kundu, A.; Vadassery, J. Chlorogenic acid-mediated chemical defence of plants against insect herbivores. Plant Biol. 2019, 21, 185-189. [CrossRef] [PubMed]

37. Slatnar, A.; Mikulic Petkovsek, M.; Halbwirth, H.; Stampar, F.; Stich, K.; Veberic, R. Enzyme activity of the phenylpropanoid pathway as a response to apple scab infection. Ann. Appl. Biol. 2010, 156, 449-456. [CrossRef]

38. Zupan, A.; Mikulic-Petkovsek, M.; Cunja, V.; Stampar, F.; Veberic, R. Comparison of phenolic composition of healthy apple tissues and tissues affected by bitter pit. J. Agric. Food Chem. 2013, 61, 12066-12071. [CrossRef] [PubMed]

39. Gutierrez, B.L.; Zhong, G.-Y.; Brown, S.K. Increased phloridzin content associated with russeting in apple (Malus domestica (Suckow) Borkh.) fruit. Genet. Resour. Crop Evol. 2018, 65, 2135-2149. [CrossRef]

40. Gosch, C.; Halbwirth, H.; Stich, K. Biosythesis, distribution and physiological relevance in plants. Phytochemistry 2010, 71, 838-843. [CrossRef]

41. Baldi, P.; Moser, M.; Brilli, M.; Vrhovsek, U.; Pindo, M.; Si-Ammour, A. Fine-tuning of the flavonoid and monolignol pathways during apple early fruit development. Planta 2017, 245, 1021-1035. [CrossRef] 